\title{
Incidence of helminthes infestation in small ruminants in three Local Government Areas of Plateau State, Nigeria
}

\author{
Gofwan, P. G. ${ }^{1}$, Sudik, S. D. ${ }^{{ }^{\star}}$, Dastu, A. J. ${ }^{1}$, Machido, H. ${ }^{1}$, Damter, S. A. ${ }^{1}$ and Magaji, S. T. ${ }^{1}$ \\ ${ }^{1}$ Department of Animal Health and Production, Plateau State College of Agriculture, Garkawa, Nigeria. \\ ${ }^{2}$ Department of Animal Science, Federal University Gashua, Yobe State, Nigeria. \\ *Corresponding author. Email: davidsudik@yahoo.com; First author’s Email: gofwanphilip@gmail.com
}

Copyright @ 2021 Gofwan et al. This article remains permanently open access under the terms of the Creative Commons Attribution License 4.0, which permits unrestricted use, distribution, and reproduction in any medium, provided the original work is properly cited.

Received 24th March, 2021; Accepted 26th April, 2021

\begin{abstract}
Sheep and goats traditionally managed are usually neglected in terms of development programmes including the determination of their parasitic loads. Therefore, this study was conducted to examine the incidence of helminthes infestation in small ruminants in three Local Government Areas (LGAs) of Plateau State, Nigeria. A total of 1800 faecal samples of sheep and goats were collected from June to September, 2020 in three Local Government areas namely Shendam, Mikang and Langtang South. Two hundred (200) samples were collected from each village given a total of 600 samples per LGA. Samples were collected inside white polythene leather, location, species, sex, age and season were carefully labeled. Microscopic examinations of faecal samples were carried out using standard laboratory methods of floatation and sedimentation techniques. Data was analyzed using Chi square test. The results showed that $60.00 \%$ of the faecal samples were infested with helminthes and $40 \%$ were negative. Majority $(34.60 \%)$ of the positive samples had mixed parasite infestations while $25.40 \%$ had singled infestations. Shendam LGA had the highest $(p<0.001)$ incidence $(78.50 \%)$ helminthes infestation while Langtang South had the lowest $(50.20 \%)$. The females' sheep and goats were significantly infested $(p<0.001, p<0.001$, respectively) higher $(61.00 \%)$ than the males $(55.20 \%)$ while the adult sheep and goats ( 7 months and above of age) were highly significantly $(p<0.001$ and $p<0.001$, respectively) infested higher $(57.40 \%$ and $63.70 \%$, respectively) than the young (0-6 months of age) $(50.60 \%$ and $60.20 \%$, respectively). The sheep and goats infested in the wet season were significantly $(p<0.001$ and $p<0.001$, respectively) higher $(76.50 \%)$ than in the dry season $(43.20 \%)$. It may be concluded that $60 \%$ of the sheep and goats studied had incidence of helminthes infestation. Therefore, proper housing, feeding, grazing systems, stocking density among other management practices are recommended to improve the productivity of sheep and goats in the area.
\end{abstract}

Keywords: Faecal samples, goat, infestation rate, management practices, productivity, sheep.

\section{INTRODUCTION}

Small Ruminant (Sheep and Goat) are the major domestic animals virtually reared in almost every household especially in the rural areas of the tropics. They play vital role in the provision of meat, milk, skin, manure, household income, employment opportunity, raw materials among others (Gana et al., 2015). Small ruminant has a great economic potential due to their high fertility, early maturity and easy adaptability to humid and semi-arid environments (Okorafor et al., 2015). However, the productions of these animals are being militated by many factors among which helminthes infestation. Gaherwal et al. (2016) accounted poor performance of small ruminants to helminthes infestation. According to Lathamani et al. (2016), the predisposing factors of helminthes parasites are grazing habit, climatic condition (temperature, rainfall, humidity), nutrient deficiency, poor management practice, pasture management among others. The commonest helminthes of sheep and goat are paramphistomiasis, fascioliasis, hemonchosis, trichostrongylosis, oesophagostomiasis, trichuris and coccidiosisas (Gana et al., 2015). Gana et al. (2015) further emphasized that in most rural communities, sheep and goat parasites are usually neglected on the assumption that sheep and goat cannot be separated from internal worms. In the light this, 
it becomes necessary to determine the incidence of helminthes infestation in small ruminants. Therefore, the objective of this study was to identify the incidence of helminthes infestation in small ruminants in three Local Government Areas (LGAs) of Plateau State, Nigeria.

\section{MATERIALS AND METHODS}

\section{Study area}

The study was conducted in Shendam, Mikang and Langtang South Local Government Areas (LGAs) of Plateau state. These three LGAs were purposively selected because of their accessibility and most of the inhabitants keep sheep and goats. These LGA are located on latitude $10^{\circ} \mathrm{N}$ and longitude $8^{\circ} \mathrm{E}$. The area usually experiences rainfall between May and October, with an annual precipitation of $1189 \mathrm{~mm}$ and dry season from November to April with an average annual temperature of $27.56^{\circ} \mathrm{C}$. Agriculture is the main source of livelihood for most of the inhabitants (Odunuga and Gbolahan, 2015).

\section{Sample collection}

A total of one thousand eight hundred (1800) faecal samples were collected from 1800 sheep and goats from June to September, 2020. In each of the LGA, three villages were randomly selected. In each village, households that had sheep and goats were identified and labeled. Thereafter, 20 households were selected using systematic sampling. In each household 5 sheep and goats each were randomly selected and one faecal sample collected from each animal; given a total of 200 samples per village and 600 samples per LGA. Samples were collected inside white polythene with location, species, sex and age carefully labeled. In regards to age, two categories were used: 0-6 months of age were designated as young and 7 months and above were designated as adults. The samples were immediately taken to the Parasitology Laboratory of the National Veterinary Research Institute, Vom, Plateau State, Nigeria. The animals were kept in both extensive and semi-extensive systems. During dry seasons the animals scavenge for food and spent the nights outside their pens whereas during raining seasons, the animals were protected by taking them to the field for grazing and housing them at night, primarily to avoid destruction of crops.

\section{Coprology}

Microscopic examinations of faecal samples were carried out using standard laboratory methods of floatation and sedimentation techniques as described by Okorafor et al. (2015). Available eggs were viewed using light microscope of varied lenses (x40).

\section{Statistical analysis}

Data collected were subjected to Chi square analysis performed by Statistical Analysis System (SAS for window version $9.4 \cup \mathrm{S} \mathrm{A}$ ).

\section{RESULTS AND DISCUSSION}

Table 1 shows the incidence of helminthes infestation in small ruminant based on location. The result showed that samples with helminthes were significantly $(p<0.001)$ higher $(60.00 \%)$ than that of negative samples $(40.00 \%)$. The $60.00 \%$ helminthes infestation observed in this study was lower than $83.08 \%$ reported by Singh et al. (2016). The variation might probably be due to the geographical location and management system. Out of the positive samples, the majority $(34.60 \%)$ had mixed helminthes infestation while samples that had single helminthes infestation constituted $(25.40 \%)$. This is comparable to the finding of Singh et al. (2016) who reported that majority of small ruminants usually have mixed helminthes with small number of animals being infested by a single helminthes. On the basis of location, Shendam LGA significantly $(p<0.001)$ had the highest incidence $(78.50 \%)$, followed by Mikang LGAs (51.30\%) while Langtang South LGA had the lowest $(50.20 \%)$. The variation observed by location in this study agreed with the report of Singh et al. (2016) that sheep and goats reared at different locations have different helminthes load. The higher incidence of the helminthes infestation in Shendam LGA than that of Langtang and Mikang LGAs might probably due to high exposure to predisposing factors such as improper grazing control and housing.

Table 2 shows the incidence of helminthes infestation on the basis of species. The helminthes infestation was significantly $(p<0.001)$ higher $(63.40 \%)$ in goats than that of sheep (56.60\%). This agreed with the report of Gana et al. (2015) that goats show high prevalence of helminthes than sheep and attributed the variation to genetic differences. Gana et al. (2015) reiterated that goats have lower resistance to gastrointestinal parasites than sheep. On the contrary, Gaherwal et al. (2016) reported that sheep were more susceptible to helminthes infestation and attributed the variation due to their close to each other during grazing and their ability to graze as close as to the ground level.

Table 3 shows incidence of gastrointestinal parasite in sheep and goats on the basis of sex. The males' sheep and goats had low infestation $(52.80 \%$ and $57.20 \%$, respectively) and their counterpart females had higher (57.40\% and $64.70 \%$, respectively). In both sheep and goats, the females significantly $(p<0.001, p<0.001$, respectively) had more infestation rate $(61.00 \%)$ than that of males (55.20\%). Similarly, Singh et al. (2013) reported that females were significantly more susceptible than males. The influence of sex on the susceptibility of animals to infestations could be attributed to genetic predisposition 
Table 1. Overall incidence of helminthes infestation in small ruminant based on location.

\begin{tabular}{|c|c|c|c|c|c|}
\hline \multirow{2}{*}{ Location (LGA) } & \multirow{2}{*}{ No examined } & \multicolumn{2}{|c|}{ Positive samples } & \multirow{2}{*}{$\begin{array}{c}\text { Total positive } \\
\text { samples }\end{array}$} & \multirow{2}{*}{$\begin{array}{c}\text { Total negative } \\
\text { samples }\end{array}$} \\
\hline & & Single parasite (\%) & Mixed parasite (\%) & & \\
\hline Shendam & 600 & $215(35.80)$ & $256(42.70)$ & $471(78.50)$ & $129(21.50)$ \\
\hline Mikang & 600 & $82(13.70)$ & $226(37.70)$ & $308(51.30)$ & $292(48.70)$ \\
\hline Langtang South & 600 & $160(26.70)$ & $141(23.50)$ & $301(50.20)$ & $299(49.80)$ \\
\hline Total & 1800 & $457(25.40)$ & $623(34.60)$ & $1080(60.00)$ & $720(40.00)$ \\
\hline
\end{tabular}

Chi square test was used. Mixed parasitic infestation contains more than one parasite viz: oesophagostomum, Coccidiaoocyst, Trichuris, Haemonchus, Moneiza, Dicrocoelium, Fasiola, Bunostonum, Trichostrogylus, Trichuris, Strongyle, Strogyloides, Amphitome.

Table 2. Incidence of gastrointestinal parasite in small ruminant based on species.

\begin{tabular}{lcccc}
\hline \multirow{2}{*}{ Species } & \multirow{2}{*}{ No examined } & \multicolumn{3}{c}{ Positive samples } \\
\cline { 3 - 5 } & & Single parasites (\%) & Mixed parasites (\%) & Total positive (\%) \\
\hline Sheep & 900 & $209(23.2)$ & $301(33.4)$ & $510(56.6)$ \\
Goat & 900 & $248(27.6)$ & $322(35.8)$ & $570(63.4)$ \\
Total & 1800 & $457(25.4)$ & $623(34.6)$ & $1080(60.0)$ \\
\hline
\end{tabular}

Chi square test was used. $\mathrm{n}=900$ per species. Mixed parasitic infestation contains more than one parasite viz: oesophagostomum, Coccidiaoocyst,Trichuris, Haemonchus, Moneiza, Dicrocoelium, Fasiola, Bunostonum, Trichostrogylus, Trichuris, Strongyle, Strogyloides, Amphitome.

Table 3. Incidence of gastrointestinal parasite in small ruminant based on sex.

\begin{tabular}{llcccc}
\hline Species & Sex & No. examined & No. positive (\%) & X $^{2}$-value & P-value \\
\hline \multirow{3}{*}{ Sheep } & Male & 144 & $76(52.80)$ & & \\
& Female & 756 & $434(57.40)$ & 1.056 & $0.001^{*}$ \\
& Total & 900 & $510(56.70)$ & & \\
\multirow{3}{*}{ Goat } & Male & 166 & $95(57.20)$ & & \\
& Female & 734 & $475(64.70)$ & 0.607 & $0.001^{*}$ \\
\hline
\end{tabular}

Chi square test was used. $n=900$ per species, ${ }^{*}$ significantly $(p<0.001)$.

Table 4. Incidence of gastrointestinal parasite in small ruminant based on age.

\begin{tabular}{llcccc}
\hline Species & Age & No examined & No positive $(\%)$ & $\mathbf{X}^{2}$-value & P-value \\
\hline \multirow{3}{*}{ Sheep } & Young & 90 & $45(50.60)$ & & \\
& Adult & 810 & $465(57.40)$ & 0.325 & 0.001 \\
& Total & 900 & $510(56.70)$ & & \\
\multirow{4}{*}{ Goat } & Young & 98 & $59(60.20)$ & & \\
& Adult & 802 & $511(63.70)$ & 0.133 & 0.001 \\
& Total & 900 & $570(63.30$ & & \\
\hline
\end{tabular}

Chi square test was used. $n=900$ per species, ${ }^{*}$ significantly $(p<0.001)$.

and differential susceptibility owing to hormonal control. The physiological peculiarities of the female animals, which usually constitute stress factors thus reducing their immunity to infestations, and for being lactating mothers, females happen to be weak and malnourished, as a result of which they are more susceptible to the infestations (Gaherwal et al., 2016; Singh et al., 2016).
Table 4 shows incidence of gastrointestinal parasites on the basis of age. The incidence rates of sheep and goats were significantly $(p<0.001$ and $p<0.001$, respectively) higher in the adults than the young ones. The young sheep and goats were 50.60 and $60.20 \%$ positive, respectively whereas the adults had 57.40 and $63.70 \%$, respectively. This agreed with the report of Velusamy et al. (2016) that 
Table 5. Incidence of gastrointestinal parasite in small ruminant based on season.

\begin{tabular}{llcccc}
\hline Species & Season & No examined & No positive (\%) & X $^{2}$-value & P-value \\
\hline \multirow{3}{*}{ Sheep } & Dry & 450 & $115(25.60)$ & & \\
& Wet & 450 & $395(87.80)$ & 352.222 & 0.001 \\
& Total & 900 & $510(56.70)$ & & \\
\multirow{4}{*}{ Goat } & Dry & 450 & $274(60.80)$ & & \\
& Wet & 450 & $296(65.80)$ & 2.110 & 0.001 \\
\hline
\end{tabular}

Chi square test was used. $n=900$ per species, ${ }^{*}$ significantly $(p<0.001)$.

adults' small ruminants above 6 months of age are more prone to gastrointestinal infestation than younger than 6 months of age. The high incidence in adults might be due to their longer exposure to the grazing fields and continual mixing of different flocks on the same grazing field. According to Dhara and Bandopadhyay (2011), stress conditions due to variable climates, long daily traveling, and gestation predispose the adults to infestations. The young animals are less susceptible to parasitic infestations due to less exposure for grazing as they mainly depend upon milk feeding (Dhara and Bandopadhyay, 2011). Yadav et al. (2006) and Emiru et al. (2013) also recorded a higher incidence of gastrointestinal parasite infestations in adults than young.

Table 5 shows incidence of gastrointestinal parasites in sheep and goats on the basis of season. There was a significant $(\mathrm{p}<0.001)$ high helminthes infestation in sheep in the wet season $(87.80 \%)$ about 3 times as in the dry season $(25.60 \%)$ whereas it was significantly $(p<0.001)$ slightly higher $(65.80 \%)$ in goats in the wet season than $60.80 \%$ in the dry season. This high incidence during the wet might be attributed to favorable climatic conditions such as humidity and temperature, supports parasitic growth, and development led to increased availability of infective larvae in this season. It is well documented that gastrointestinal parasitism in grazing animals is directly related to the availability of larvae on pasture and seasonal pasture contamination (Varadharajan and Vijayalakshmi, 2015). According to Emiru et al. (2013), climatic factors influence larval dispersion on the herbage which increases the chance of contact between host and larvae. Low infestation of parasites during the dry season might probably due to insufficient lush pastures as described by Dhara and Bandopadhyay (2011). As measures of controlling gastrointestinal parasites in sheep and goats, Lathamani et al. (2016) and Emiru et al. (2013) suggested total confinement and/or regular deworming and the treatment of grazing areas.

\section{Conclusion}

The presence study revealed that out of the 1800 samples studied $60.00 \%$ was positive and $40 \%$ negative. In regard to species, the helminthes infestation was higher $(63.40 \%)$ in goats and lower (56.60\%) in sheep. In regard to sex, female sheep and goats had higher $(57.40 \%$ and $64.70 \%$, respectively) incidence than their counterpart males (52.80\% and $57.20 \%$, respectively). In regard to age, there were high $(57.40 \%$ and $63.70 \%)$ incidence in sheep and goats respectively and lower in the young sheep and goats (50.60\% and $60.20 \%$, respectively). In regard to season, there was very high helminthes infestation in sheep in the wet season $(87.80 \%)$ than in the dry season $(25.60 \%)$ and a slightly higher $(65.80 \%)$ incidence in goats in the wet season than $60.80 \%$ in the dry season. Therefore, proper housing, feeding, grazing systems, stocking density among other management practices bearing in mind species, sex, age distribution and seasonal influence.

\section{CONFLICT OF INTEREST}

The authors declare that there is no conflict of interest.

\section{REFERENCES}

Dhara, K. C., \& Bandopadhyay, P. K. (2011). Influence of gastrointestinal parasites on the productive and reproductive performances of Black Bengal goat under field conditions. International Journal of Science Nature, 2(3), 638647.

Emiru, B., Amede, Y., Tigre, W., Feyera, T., \& Deressa, B. (2013). Epidemiology of gastrointestinal parasites of small ruminants in Gechi District, Southwest Ethiopia. Advance Biology Research, 7(5), 169-174.

Gana, J. J., Makun, H., Chiezey, N. P., \& Tekdek, L. B. (2015). Epidemiological study on abomasal nematodes of slaughtered small ruminantsraised in guinea savanna zone of Nigeria. Sokoto Journal of Veterinary Sciences, 13(2), 26-33

Gaherwal, S., Prakash, M. M., \& Dudwe, J. (2016). Incidence and incidence of nematodes in goats at five different villages of Barwani district, Mathya Pradesh. International Journal of Advance Resources, 4(3), 1126-1137.

Lathamani, V. S., Ramesh, P. T., \& Siddalingamurthy, H. K. (2016). Studies on the incidence of helminth infestation in small ruminants and the anthelmintic effectiveness in Tumkur District of Karnataka. International Journal of Innovation Research Science Engineer Technology, 5(2), 2169-2173. 
Okorafor, U. P., Obebe, O. O., Unigwe, C. R., Atoyebi, T. J., \& Ogunlaye, O. K. (2015). Studies on the gut parasites of small ruminants reared in some selected farms in Ido Local government area of Oyo state Nigeria. Applied Research Journal, 1(3), 153-159.

Odunuga, S., \& Badru, G. (2015). Landcover change, land surface temperature, surface albedo and topography in the Plateau Region of North-Central Nigeria. Land, 4(2), 300-324.

Singh, R., Varshney, P., Dash, S. K., \& Lal, H. P. (2013). Incidence of gastrointestinal parasites in sheep and goats in and around Mathura, India. Veterinary World, 6(5), 260-262.

Singh, R., Kaur, P., Singla, L. D., \& Bal, M. S. (2016). Prevalence of gastrointestinal parasitism in small ruminant in western zone of Punjab, India. Veterinary World, 10(1), 61-66.
Varadharajan, A., \& Vijayalakshmi, R. (2015). Incidence and seasonal occurrence of gastrointestinal parasites in small ruminants of coastal areas of Tamil Nadu. Intentional Journal of Science Research and Publication, 5(2), 1-5.

Velusamy, R., Rani, N., Ponnudurai, G., \& Anbarasi, P. (2016). Incidence of intestinal and haemoprotozoan parasites of small ruminants in Tamil Nadu, India. Veterinary World, 8(10), 12051209.

Yadav, A., Khajuria, J. K. and Raina, A. K. (2006). Seasonal incidence of gastrointestinal parasites in sheep and goats of Jammu. Journal of Veterinary Parasitology, 20(1), 65-68. 